\title{
Molecular Chaperones and Quality Control in Noncoding RNA Biogenesis
}

\author{
S.L. WOLIN*† AND E.J. WURTMANN* \\ *Departments of Cell Biology and Molecular Biophysics and Biochemistry, \\ Yale University School of Medicine, New Haven, Connecticut 06536
}

\begin{abstract}
Although noncoding RNAs have critical roles in all cells, both the mechanisms by which these RNAs fold into functional structures and the quality control pathways that monitor correct folding are only beginning to be elucidated. Here, we discuss several proteins that likely function as molecular chaperones for noncoding RNAs and review the existing knowledge on noncoding RNA quality control. One protein, the La protein, binds many nascent noncoding RNAs in eukaryotes and is required for efficient folding of certain pre-tRNAs. In prokaryotes, the Sm-like protein Hfq is required for the function of many noncoding RNAs. Recent work in bacteria and yeast has revealed the existence of quality control systems involving polyadenylation of unstable noncoding RNAs followed by exonucleolytic degradation. In addition, the Ro protein, which is present in many animal cells and also certain bacteria, binds misfolded noncoding RNAs and is proposed to function in RNA quality control.
\end{abstract}

All cells contain an enormous variety of noncoding RNAs that have critical roles in gene expression. In the nucleus, the telomerase RNA is required to maintain chromosome ends, the 7SK RNA regulates transcription elongation, and U small nuclear RNAs (snRNAs) are key components of the spliceosome. The nucleolus contains a truly large number of small nucleolar RNAs (snoRNAs) that guide the processing and modification of the large ribosomal RNAs. In the cytoplasm, rRNAs and tRNAs are essential for protein synthesis, and the 7SL RNA-containing signal recognition particle targets newly synthesized presecretory proteins to the endoplasmic reticulum. In addition, numerous microRNAs (miRNAs) base-pair with mRNAs, regulating both stability and translation (Storz et al. 2005).

To function, many noncoding RNAs must fold into intricate structures and assemble with both proteins and other RNAs. As several studies have revealed that RNA has a tendency to become kinetically trapped in nonfunctional structures in vitro, it is likely that RNA-binding proteins assist RNA folding in cells (Herschlag 1995; Schroeder et al. 2004). RNA-binding proteins could act in several ways to facilitate formation of native RNAs. Specific RNA-binding proteins that are part of the final ribonucleoprotein complex may stabilize bound RNAs in the correct conformation. On the basis of crystallographic analyses, such a role has been proposed for many ribosomal proteins (Moore and Steitz 2003). Alternatively, similar to the molecular chaperones that function in protein folding, RNA-binding proteins that are not part of the final assembly could assist correct folding or resolve misfolded structures. Proteins that may function in this way include members of the DExH/D box family of RNAdependent ATPases. One member of this family, Neurospora crassa CYT-19, disrupts alternative RNA structures that function as kinetic traps during the folding of a group I intron (Mohr et al. 2002). A related protein,
Mss116p, is required for efficient splicing of group I and group II introns in Saccharomyces cerevisiae (Huang et al. 2005). Another protein that may assist RNA folding through transient binding and release of nascent RNAs is the eukaryotic La protein, which binds the 3' ends of many nascent noncoding RNAs and is often removed during 3' maturation (Wolin and Cedervall 2002; Chakshusmathi et al. 2003). Finally, RNA-binding proteins, such as Escherichia coli Hfq, a member of the Smlike family of proteins, can facilitate formation of intermolecular RNA-RNA interactions that are essential for function (Moller et al. 2002; Zhang et al. 2002).

In addition to mechanisms to assist correct folding, cells also possess RNA quality control systems to recognize and degrade misfolded and otherwise aberrant noncoding RNAs. Mutations that cause misfolding can result from gene mutations, transcriptional errors, or posttranscriptional editing events. Errors in RNA processing, failure to correctly assemble with proteins, and exposure to reactive oxygen species or other RNA-damaging agents can also result in nonfunctional RNAs. Some of the cellular mechanisms by which incorrectly folded and otherwise defective noncoding RNA molecules are recognized and degraded have been described. In both E. coli and yeast, degradation of several aberrant noncoding RNAs involves polyadenylation of the $3^{\prime}$ ends, followed by exoribonuclease digestion (Anderson 2005). However, as several yeast noncoding RNAs are degraded independently of this pathway (Alexandrov et al. 2006; Copela et al. 2006), additional quality control components remain to be uncovered.

In this paper, we examine the roles of the La and Smlike proteins in assisting noncoding RNA biogenesis and function. We also discuss the existing information on quality control pathways for noncoding RNAs. A particular focus is the Ro protein, which binds misfolded noncoding RNAs and likely forms part of an RNA quality control pathway in animal cells. 


\section{LA STABILIZES NASCENT NONCODING RNAS AND ASSISTS PRE-TRNA FOLDING}

The La protein binds to the 3' ends of many newly synthesized noncoding RNAs, stabilizing them against exonucleases (Wolin and Cedervall 2002). Because La recognizes the sequence $\mathrm{UUU}_{\mathrm{OH}}$, which is the initial terminus of all RNAs synthesized by RNA polymerase III, RNAs bound include pre-tRNAs, pre-5S rRNAs, pre-U6 snRNA, pre-7SL RNA, and pre-RNase P RNA. As the majority of these RNAs undergo some form of 3' processing, La is usually not bound to the mature RNAs. In the yeast $S$. cerevisiae, La also binds many noncoding RNAs synthesized by RNA polymerase II, including the spliceosomal U snRNAs and a number of snoRNAs (Wolin and Cedervall 2002; Inada and Guthrie 2004). In contrast to the RNA polymerase-III-transcribed RNAs, these RNAs are not primary transcripts, but represent partly processed RNAs that end in $\mathrm{UUU}_{\mathrm{OH}}$. As 3' shortened forms of many nascent noncoding RNAs are detected in cells lacking La, binding by La normally stabilizes these RNAs from exonucleolytic digestion, favoring correct processing (Wolin and Cedervall 2002).

In addition to its role in protecting $3^{\prime}$ ends of nascent RNAs, La contributes to correct folding of certain pretRNAs. Although La is not essential in budding or fission yeast, La becomes essential in the presence of mutations that compromise pre-tRNA structure (Yoo and Wolin 1997; Johansson and Bystrom 2002; Chakshusmathi et al. 2003). For many of these mutations, the affected pretRNA is unstable without La, making it difficult to determine whether the instability is caused by misfolding, rather than the loss of end protection. However, for pretRNA $\mathrm{Crg}_{\mathrm{C}}^{\mathrm{Arg}}$, which contains a structurally fragile anticodon stem, La is required for efficient folding at low temperature or when the pre-tRNA structure is further perturbed by mutation (Fig. 1A) (Chakshusmathi et al. 2003). Chemical and enzymatic footprinting experiments suggest that in addition to binding pre-tRNA $3^{\prime}$ ends, La contacts and stabilizes the correctly folded anticodon stem-loop (Chakshusmathi et al. 2003).

Recent structural and biochemical studies have revealed how La protects 3' termini from exoribonucleases. All La proteins contain three domains: an amino-terminal La motif, which adopts a winged helix fold (Alfano et al. 2004; Dong et al. 2004); a central RNA recognition motif (RRM); and a highly charged carboxyl terminus. Many La proteins also contain another RRM in the carboxyl terminus (Wolin and Cedervall 2002). Biochemical studies demonstrated that both the La motif and the central RRM are required for high-affinity binding (Goodier et al. 1997; Dong et al. 2004). A recent crystal structure of the human La motif and central RRM complexed to an oligonucleotide terminating in uridines revealed that the $\mathrm{UUU}_{\mathrm{OH}}$ binds in a cleft formed by the La and RRM motifs (Teplova et al. 2006). As anticipated from mutagenesis (Dong et al. 2004), the majority of the hydrogen bonds and stacking interactions with the $\mathrm{UUU}_{\mathrm{OH}}$ are from the $\mathrm{La}$ motif. The unusual ability of La to discriminate between RNAs ending in $\mathrm{UUU}_{\mathrm{OH}}$ and $\mathrm{UUU}_{\mathrm{p}}$, which may help distinguish nascent RNA polymerase III transcripts from degraded RNAs, is partly due to a hydrogen bond between the $3^{\prime} \mathrm{OH}$ and a conserved aspartate in the La motif (Dong et al. 2004; Teplova et al. 2006).

How might La stabilize correctly folded pre-tRNAs? As RNA footprinting experiments reveal that $S$. cerevisiae $\mathrm{La}$ protects the acceptor stem and the anticodon stem-loop of pre-tRNA ${ }_{C C G}^{\mathrm{Arg}}$ from nucleases, these regions may be in close contact with La (Chakshusmathi et al. 2003). Since the typical RNA interaction surface of the central RRM, a four-stranded antiparallel $\beta$-sheet, does not contact the 3' uridylates (Teplova et al. 2006), it could stabilize other pre-tRNA elements. Consistent with this hypothesis, conserved residues in the RRM are necessary for maturation of several structurally impaired pre-tRNAs in Schizosaccharomyces pombe (Huang et al. 2006). Similarly, as the usual surface used by winged helix domain proteins to recognize double-stranded DNA is not involved in binding of La to 3' ends (Dong et al. 2004; Teplova et al. 2006), this surface may be involved in other interactions. Finally, the carboxyl terminus, which is rich in lysines and arginines, could stabilize correctly folded RNAs. Clearly, a full description of how La stabilizes correctly folded pre-tRNAs will require a structure of the complex.

Although La is essential for viability in both mice and trypanosomes (Arhin et al. 2005; Foldynova-Trantirkova et al. 2005; Park et al. 2006), the finding that La is dispensable in two yeasts suggests that other proteins function redundantly with $\mathrm{La}$ in noncoding RNA biogenesis. To identify these components, our laboratory carried out genetic screens to identify mutations that cause $S$. cerevisiae La to become essential (Table 1). One class of mutations resided in essential tRNA genes, resulting in pre-tRNAs that were unstable without La (Yoo and Wolin 1997; Chakshusmathi et al. 2003). Other mutations were in proteins that, like La, contact newly synthesized noncoding RNAs. For example, La is required for viability in the presence of mutations in members of the Sm and Smlike family of proteins (Pannone et al. 1998, 2001; Xue et al. 2000). Analyses of the mutant strains revealed that La stabilizes nascent U6 snRNAs when cells contain mutations in components of the Lsm2-Lsm8 ring (Pannone et al. 1998, 2001) and that La assists assembly of the U4 snRNA into the U4/U6 snRNP when cells contain a mutation in the snRNP core protein Smd1p (Xue et al. 2000). La is also important for growth when cells contain mutations in the arginyl tRNA synthetase or either of two tRNA modification enzymes, Trm1p and Trm61p (Calvo et al. 1999; Copela et al. 2006). Taken together, these experiments suggest that La functions redundantly with other proteins that contact nascent RNAs to stabilize these RNAs and assist their assembly into functional RNPs.

\section{SM-LIKE PROTEIN RINGS MAY FACILITATE RNA-RNA INTERACTIONS}

A family of proteins that stabilizes bound noncoding RNAs from nucleases, assists intermolecular base-pairing, and may modulate RNA structure are the Sm-like proteins. These proteins, which contain the Sm fold pre- 
A

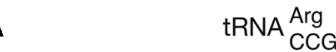

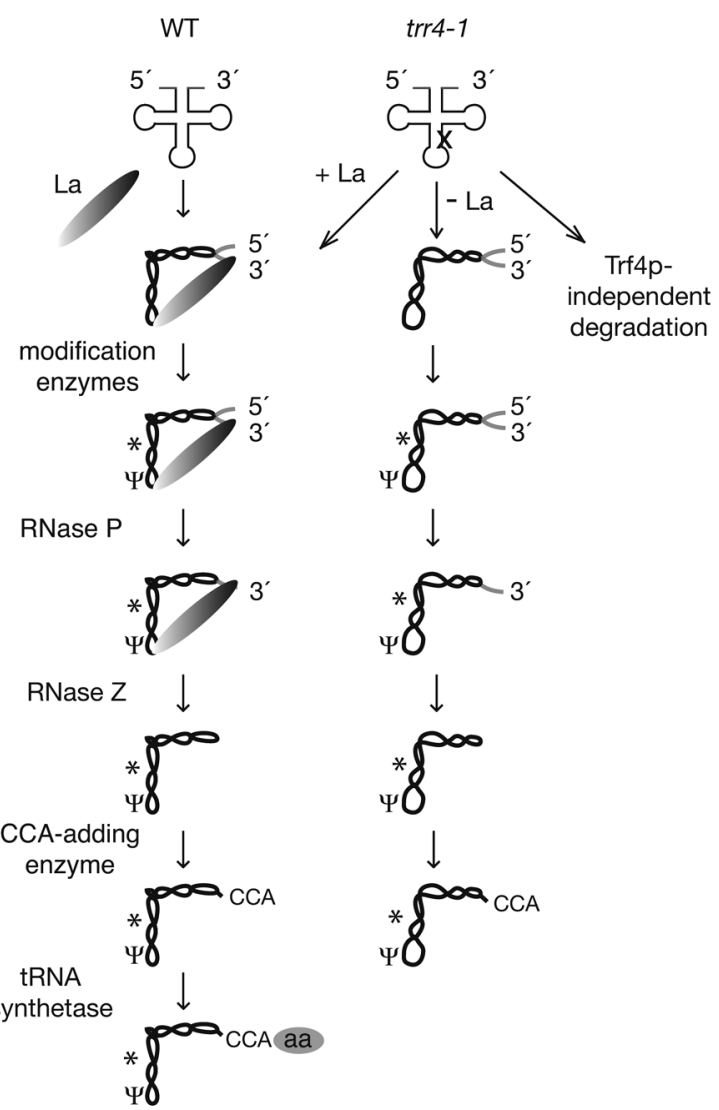

B tRNA ${ }_{i}^{\text {Met }}$

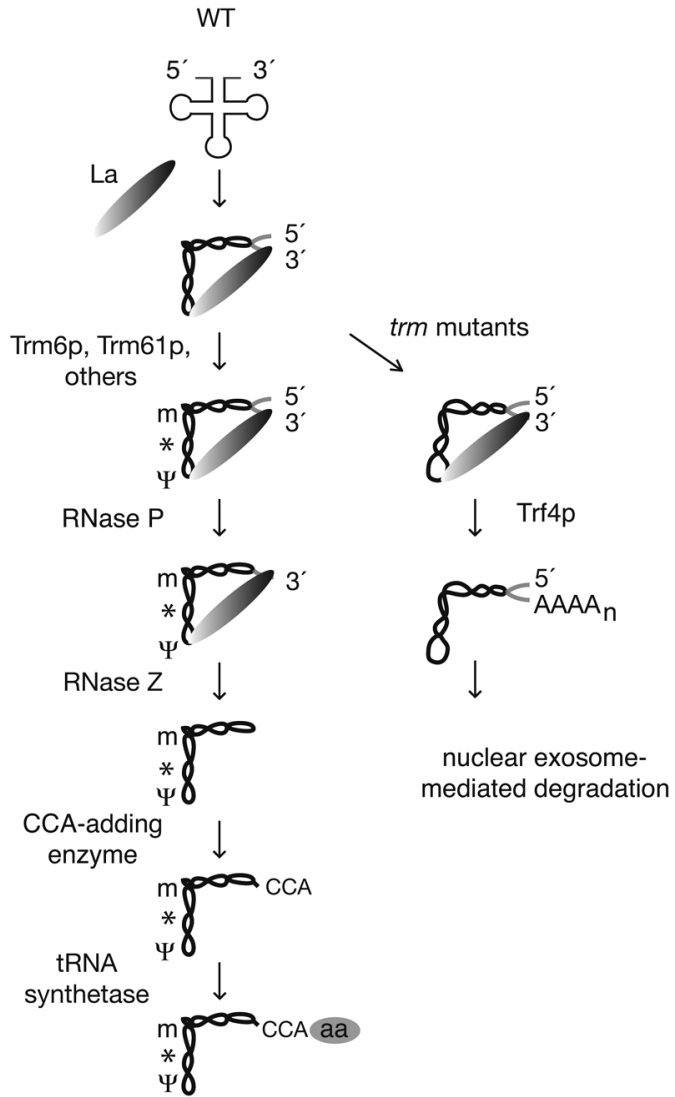

Figure 1. Biogenesis of tRNA $A_{C E G}^{A r g}$ and tRNA $A_{i}^{\mathrm{Met}}$. (A) La is required for efficient folding of yeast tRNA ${ }_{C C G}^{\mathrm{Arg}}$. After removal of the $5^{\prime}$ leader by RNase P, cleavage of the $3^{\prime}$ trailer by an endonuclease such as RNase Z, and modification of multiple nucleotides (which occurs both before and after end maturation), tRNAs undergo CCA addition and aminoacylation. In yeast lacking La (not shown), the $3^{\prime}$ trailer is removed by exonucleases (Yoo and Wolin 1997). In yeast containing the trr4-1 mutation, which disrupts the anticodon stem of tRNA Arg In the absence of La, the anticodon stem misfolds, and the mature tRNA is not aminoacylated (Chakshusmathi et al. 2003). In addition to the requirement for La, the trr4-1 mutation causes a fraction of the mutant tRNA to be unstable. Degradation of the mutant tRNA does not require the Trf4 polymerase (Copela et al. 2006). (B) Methylation of adenosine 58 is required for stable accumulation of tRNA $\mathrm{A}_{\mathrm{i}}^{\mathrm{Met}}$. In yeast carrying mutations in either TRM6 or TRM61, which encode the two subunits of the tRNA $\left(\mathrm{m}^{1} \mathrm{~A} 58\right)$ methyltransferase (Anderson et al. 2000), the hypomethylated pre-tRNA $\mathrm{i}_{\mathrm{i}}^{\text {Met }}$ undergoes polyadenylation by Trf4p and degradation by the nuclear exosome (Kadaba et al. 2004, 2006). As overexpression of $L H P 1$, which encodes yeast La, results in increased levels of both pre- and mature tRNA $\mathrm{Met}_{\mathrm{i}}$ in trm6 strains (Anderson et al. 1998), binding by La may interfere with polyadenylation and/or exonucleolytic degradation. Consistent with this hypothesis, strains containing a mutation in TRM61 and also lacking LHPI exhibit reduced growth and decreased tRNA $\mathrm{i}_{\mathrm{i}}^{\text {Met }}$ (Calvo et al. 1999).

Table 1. Mutations That Cause La to Become Important or Essential for Growth in S. cerevisiae

\begin{tabular}{|c|c|c|}
\hline Gene & Product & Reference \\
\hline sup61 $1^{+}$ & $\mathrm{tRNA}_{\mathrm{CGA}}^{\mathrm{Ser}}$ & Yoo and Wolin (1997) \\
\hline$T R T 2$ & tRNA ${ }_{C G U}^{T h r}$ & Chakshusmathi et al. (2003) \\
\hline TRR4 & tRNA $\mathrm{ACG}_{\mathrm{C} g}$ & Chakshusmathi et al. (2003) \\
\hline TRM61 & tRNA (m $\left.{ }^{1} \mathrm{~A} 58\right)$ methyltransferase subunit & Calvo et al. (1999) \\
\hline TRM1 & tRNA $\left(\mathrm{m}_{2}^{2} \mathrm{G}\right)$ dimethyltransferase & Copela et al. (2006) \\
\hline RRS1 & Arginyl-tRNA synthetase & Copela et al. (2006) \\
\hline SMD1 & snRNP core protein Smdlp & Xue et al. (2000) \\
\hline LSM5 & Sm-like protein, component of U6 snRNP & Pannone et al. (2001) \\
\hline LSM6 & Sm-like protein, component of U6 snRNP & Pannone et al. (2001) \\
\hline LSM7 & Sm-like protein, component of U6 snRNP & Pannone et al. (2001) \\
\hline LSM8 & Sm-like protein, component of U6 snRNP & Pannone et al. $(1998,2001)$ \\
\hline
\end{tabular}


sent in the core proteins of the spliceosomal U1, U2, U4, and U5 snRNPs, associate to form six- or seven-membered rings. Sm-like proteins are evolutionarily ancient, as orthologs are present in all sequenced eukaryotic genomes, as well as in certain archaebacteria and eubacteria (Salgado-Garrido et al. 1999; Moller et al. 2002; Zhang et al. 2002). In eukaryotes, Sm-like proteins form several distinct complexes. One complex, consisting of the Lsm2-Lsm8 proteins ( $\mathrm{Lsm}=$ like Sm), stabilizes the 3' end of the spliceosomal U6 snRNA and assists basepairing with U4 RNA to form the U4/U6 snRNP (Pannone et al. 1998; Achsel et al. 1999; Mayes et al. 1999; Salgado-Garrido et al. 1999). A second complex, formed by Lsm1-Lsm7, binds the 3' ends of deadenylated mRNAs and assists mRNA decapping (Tharun et al. 2000; He and Parker 2001). A third complex, containing the six proteins Lsm2-Lsm7, binds the yeast small nucleolar RNA snR5, which functions in pseudouridylation of rRNA (Fernandez et al. 2004). Two Sm-like proteins also associate with five bona fide $\mathrm{Sm}$ proteins to form the core of the U7 snRNP, which base-pairs with histone premRNA to direct the endonucleolytic cleavage required for mRNA 3' end formation (Schumperli and Pillai 2004).

To date, the best-studied Sm-like protein ring is formed by $E$. coli Hfq. In contrast to the heteroheptameric rings found in eukaryotes, Hfq is a homohexamer (Fig. 2A). Hfq binds more than 20 noncoding RNAs in E. coli, most of which function by base-pairing with other RNAs, usually mRNAs (Zhang et al. 2003; Storz et al. 2005). For at least some of these RNAs, Hfq assists base-pairing of the noncoding RNA with its target (Moller et al. 2002; Zhang et al. 2002). Hfq also protects many bound noncoding RNAs from digestion by the endoribonuclease RNase E (Moll et al. 2003b; Zhang et al. 2003).

How does Hfq binding facilitate base-pairing of noncoding RNAs with their targets? For some mRNAs, Hfq alters the secondary structure of the mRNA, resulting in increased accessibility of the targeted sequence (Moll et al. 2003a; Geissmann and Touati 2004). For other mRNAs, no structural changes have been detected upon Hfq binding (Brescia et al. 2003; Lease and Woodson 2004). An alternative but not exclusive possibility is that Hfq accelerates base-pairing by bringing the two RNAs into proximity. Consistent with this idea, mutagenesis studies indicate that Hfq has two independent RNA-binding surfaces (Mikulecky et al. 2004). It is also possible that two Hfq rings interact with each other, bringing their individually bound RNAs together (Storz et al. 2004). A "two-ring" mechanism would be consistent with the fact that in eukaryotes, the various spliceosomal snRNAs that interact through base-pairing, such as the U4 and U6 snRNAs and the U2 and U6 snRNAs, are each bound by an $\mathrm{Sm}$ or Sm-like protein ring.

Do the eukaryotic Sm and Lsm proteins also modulate RNA structure and assist base-pairing? Because many of the RNAs bound by these proteins function by base-pairing with other RNAs, it has been proposed that these rings, similar to Hfq, facilitate annealing of the bound RNAs with their target sequences (Moller et al. 2002; Zhang et al. 2002). Support for this hypothesis comes from experiments showing that the Lsm2-Lsm8 complex
A

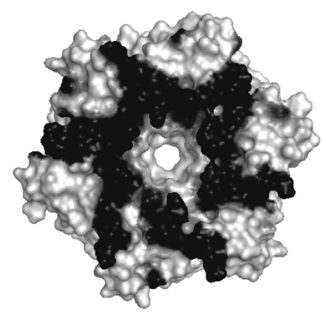

B

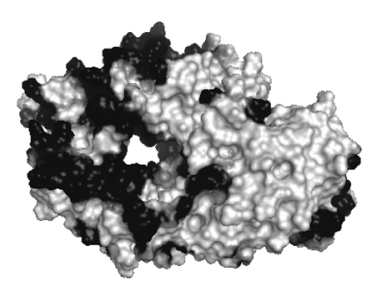

Figure 2. Hfq and Ro form rings of similar size. Staphylococcus aureus Hfq (panel $A$; see Schumacher et al. 2002) forms a homohexamer of $54 \mathrm{kD}$, which is similar in size to the monomeric ring formed by the $X$. laevis $60-\mathrm{kD}$ Ro protein (panel $B$; see Stein et al. 2005). Surfaces with positive electrostatic potential are shown (dark shading). Both proteins have two RNA-binding sites. For Hfq, one binding site is around the central cavity and a second is on the distal face of the ring (Schumacher et al. 2002; Mikulecky et al. 2004). For Ro, the $3^{\prime}$ ends of misfolded RNAs insert into the hole, whereas helical portions bind to basic patches on the outer surface that overlap the Y RNA-binding site (Stein et al. 2005; Fuchs et al. 2006). The figure was prepared using MacPyMOL (DeLano Scientific LLC, San Carlos, California).

enhances U4:U6 annealing in vitro (Achsel et al. 1999), and that these Lsm proteins are required for multiple rounds of splicing in vitro (Verdone et al. 2004). Because both the Lsm1-Lsm7 and the Lsm2-Lsm8 complexes have recently been reconstituted from recombinant proteins (Zaric et al. 2005), information should soon be forthcoming as to whether these complexes, like Hfq, can alter RNA structure and enhance a variety of RNA-RNA interactions.

\section{SIMILAR PATHWAYS FOR NONCODING RNA QUALITY CONTROL IN BACTERIA AND YEAST}

Some of the first insights into how defective noncoding RNAs are targeted for decay came from experiments in $E$. coli. A mutant structurally unstable form of tRNA ${ }^{\operatorname{Trp}}$ was found to be degraded through a pathway involving polyadenylation of the pre-tRNA by poly(A) polymerase (PAP) and degradation by the $3^{\prime}$ to $5^{\prime}$ exoribonuclease polynucleotide phosphorylase (PNPase) (Li et al. 2002). PNPase also functions with another exoribonuclease, RNase $\mathrm{R}$, to degrade defective rRNAs (Cheng and Deutscher 2003). Although a requirement for polyadenylation in rRNA decay has not been reported, pre-23S rRNAs and 16S rRNAs containing short poly(A) tails have been observed in E. coli (Mohanty and Kushner 1999). Moreover, both overexpression of PAP and the absence of processing exoribonucleases result in accumulation of polyadenylated pre-23S rRNAs (Li et al. 1998; Mohanty and Kushner 1999), suggesting that a balance normally exists between processing and polyadenylation of precursors. In E. coli, polyadenylation acts as a signal for both mRNA and noncoding RNA decay and assists 3' to $5^{\prime}$ exoribonucleases in initiating decay of structured RNAs by providing a single-stranded 3' end (Deutscher 2006). Interestingly, Hfq copurifies with PAP and 
PNPase and is required for the efficient polyadenylation of mRNAs that contain Rho-independent transcription terminators (Mohanty et al. 2004). Although Hfq is not required for the polyadenylation of pre-23S rRNAs, the finding that a chaperone protein is necessary to recruit PAP to some mRNAs highlights the question of whether polyadenylation of noncoding RNAs is stochastic or the result of recruitment.

A remarkably similar system for noncoding RNA quality control occurs in the yeast $S$. cerevisiae. A nuclear poly(A) polymerase, Trf4p, was found to function with the exosome, a complex of $3^{\prime}$ to $5^{\prime}$ exoribonucleases, to degrade a hypomethylated unstable pre-tRNA (Fig. 1B) (Kadaba et al. 2004). Trf4p is part of a complex called TRAMP, which also contains one of two likely RNAbinding proteins, Air1p and Air2p, and an RNA helicase, Mtr4p (LaCava et al. 2005; Vanacova et al. 2005; Wyers et al. 2005). In addition to targeting unstable pre-tRNAs for decay, TRAMP is involved in the decay of a mutant U6 snRNA, several precursors to rRNAs and snRNAs, and transcripts of intergenic regions (LaCava et al. 2005; Wyers et al. 2005; Kadaba et al. 2006). Yeast also contain a related poly(A) polymerase complex, consisting of the Trf4p-related protein Trf5p, Air1p, and Mtr4p, that has overlapping functions with the TRAMP complex (Egecioglu et al. 2006; Houseley and Tollervey 2006; Kadaba et al. 2006).

How the Trf4p and Trf5p poly(A) polymerases recognize defective RNAs is currently unknown. Because these polymerases lack the RNA-binding domain found in canonical poly(A) polymerases that act on mRNA, Air1p and Air $2 p$ are proposed to function in substrate recognition (Vanacova et al. 2005). In vitro, the TRAMP complex polyadenylates a structurally compromised mutant tRNA more efficiently than the wild-type tRNA (Vanacova et al. 2005). However, the natural tRNA targets of Trf4 $p$ polyadenylation are nascent pre-tRNAs containing both 5 ' leader and 3' trailer sequences (Kadaba et al. 2006). One possibility is that mutant pre-tRNAs that fail to be processed by the endonucleases that catalyze 5 and 3' maturation are preferentially targeted for decay because they accumulate as precursors. Similarly, mutant forms of U6 snRNA that are less efficient in their assembly with specific RNA-binding proteins, such as the Lsm2-Lsm8 complex, could be targets. Since the $3^{\prime}$ ends of many nascent noncoding RNAs are normally bound by proteins such as La, one possibility is that Trf4p may preferentially adenylate RNAs containing 3 ' extensions that are not bound by proteins.

Although the Trf4p- and Trf5p-containing poly(A) polymerases function in the decay of a large number of yeast noncoding RNAs, the role of these polymerases in noncoding RNA quality control is not universal. A hypomodified tRNA $\mathrm{VAa}$ that is unstable at $37^{\circ} \mathrm{C}$ is degraded through a pathway that does not require $\operatorname{Trf} 4 \mathrm{p}$, Trf5p, or Rrp6p, a component of the nuclear exosome (Alexandrov et al. 2006). Similarly, two unstable mutant forms of tRNA ${ }_{\text {CCG }}^{\mathrm{Arg}}$ are degraded independently of Trf4p (Fig. 1A) (Copela et al. 2006). At least for tRNA $\mathrm{V}_{\mathrm{ACC}}$, degradation occurs at the level of the mature tRNA, rather than the pre-tRNA (Alexandrov et al. 2006). Defining these addi- tional decay pathways will likely be the focus of much effort in coming years. In addition, it will be important to elucidate how La, which binds many nascent noncoding RNAs, interfaces with Trf4p and other quality control pathways that monitor RNA integrity.

\section{Ro BINDS MISFOLDED NONCODING RNAS AND LIKELY FUNCTIONS IN QUALITY CONTROL}

A protein that likely functions in noncoding RNA quality control is the Ro $60-\mathrm{kD}$ protein. This protein is found in both the nucleus and cytoplasm of many animal cells. In the cytoplasm, Ro is complexed with noncoding RNAs called Y RNAs. In the nucleus, Ro associates with misfolded RNAs that are, at least in some cases, targeted for decay. In Xenopus oocyte nuclei, Ro binds a large collection of variant pre-5S rRNAs that misfold into nonfunctional structures (O'Brien and Wolin 1994; Shi et al. 1996). These variant RNAs also contain 8-10 additional nucleotides at the $3^{\prime}$ end, due to readthrough of the first RNA polymerase III transcription termination signal. Consistent with a general role in noncoding RNA quality control, Ro associates with variant misfolded U2 snRNAs in mouse embryonic stem cells (Chen et al. 2003).

Biochemical and structural studies have addressed how Ro recognizes its various RNA substrates. The amino-terminal two thirds of Ro consists of a series of $\alpha$-helical HEAT repeats that form a ring with a central cavity (Fig. 2B) (Stein et al. 2005). The central cavity is approximately $10-15 \AA$ in diameter and is lined with lysines and arginines. The HEAT repeat ring is clasped shut by a von Willebrand Factor A (vWFA) domain (Stein et al. 2005), which is also found in integrins and other proteins involved in cell adhesion. Within the vWFA domain is a MIDAS (metal-ion-dependent adhesion site) motif, which in integrins is a divalent-cation-dependent ligandbinding site and also transmits conformational changes that accompany ligand binding (Shimaoka et al. 2002).

A crystal structure of Ro complexed with a fragment of Y RNA revealed that Ro contains two RNA-binding sites (Fig. 2B) (Stein et al. 2005). Y RNA binds on the outer surface of the ring. A second RNA-binding site occurs within the channel, as a single-stranded RNA derived from one of the oligomers used to form the Y RNA fragment was present inside the central cavity. Biochemical experiments suggested that the 3' ends of misfolded RNAs normally insert into the cavity and that helical portions of these RNAs bind on the outer surface. Because the binding sites of the Y RNAs and the misfolded RNAs overlap on the outer surface, Y RNAs were proposed to regulate access of Ro to other RNAs (Stein et al. 2005).

As with the Trf4p poly(A) polymerase, a major question concerns how Ro recognizes misfolded RNAs. Using misfolded pre-5S rRNA as a model, our laboratory found that Ro binds RNAs that contain both a single-stranded 3' end and helical elements (Fuchs et al. 2006). As predicted from mutagenesis, a crystal structure of Ro bound to a fragment of misfolded pre-5S rRNA revealed that the single-stranded 3' end binds in the central cavity, whereas an adjacent helix binds to a large basic platform on the sur- 
face of the ring. Because many of the contacts between Ro and the misfolded RNA are not sequence-specific, these experiments suggest that Ro may scavenge noncoding RNAs that fail to be bound by their specific RNA-binding proteins (Fuchs et al. 2006). Consistent with this hypothesis, the misfolded pre-5S rRNAs are poorly recognized by the 5S rRNA-binding protein TFIIIA in vivo (O'Brien and Wolin 1994).

What are the fates of the misfolded RNAs bound by Ro? In Xenopus laevis oocytes, the misfolded pre-5S rRNAs are inefficiently processed and eventually degraded (O’Brien and Wolin 1994). Thus, one possibility is that Ro recruits exonucleases, thus targeting associated noncoding RNAs for decay. An alternative but not exclusive possibility is that binding by Ro to the singlestranded ends of noncoding RNAs destabilizes adjacent helices, thus assisting in either degradation by exonucleases or refolding to functional forms.

\section{CONCLUSIONS}

Despite the importance of noncoding RNAs for many aspects of gene expression, much remains to be learned about both their mechanisms of folding within cells and the quality control pathways that monitor correct folding and RNP assembly. For mRNAs, it is well-established that the processes of transcription, RNP assembly, RNA processing, RNA export, and mRNA translation all interface with surveillance pathways. Far less is known as to how these steps in noncoding RNA biogenesis are monitored for formation of functional RNAs. Nonetheless, the recent identification of several components of noncoding quality control pathways has begun to yield information as to how defective noncoding RNAs and improperly assembled RNPs are recognized and handled, which should in turn result in a more complete understanding of noncoding RNA biogenesis.

\section{ACKNOWLEDGMENTS}

Work in our laboratory is supported by National Institutes of Health grants GM073863 and GM48410. E.W. is supported by a predoctoral fellowship from the National Science Foundation.

\section{REFERENCES}

Achsel T., Brahms H., Kastner B., Bachi A., Wilm M., and Luhrmann R. 1999. A doughnut-shaped heteromer of human Sm-like proteins binds to the 3 '-end of U6 snRNA, thereby facilitating U4/U6 duplex formation in vitro. EMBOJ. 18: 5789.

Alexandrov A., Chernyakov I., Gu W., Hiley S.L., Hughes T.R., Grayhack E.J., and Phizicky E.M. 2006. Rapid tRNA decay can result from lack of nonessential modifications. Mol. Cell 21: 87.

Alfano C., Sanfelice D., Babon J., Kelly G., Jacks A., Curry S., and Conte M.R. 2004. Structural analysis of cooperative RNA binding by the La motif and central RRM domain of human La protein. Nat. Struct. Mol. Biol. 11: 323.

Anderson J.T. 2005. RNA turnover: Unexpected consequences of being tailed. Curr. Biol. 15: R635.

Anderson J., Phan L., and Hinnebusch A.G. 2000. The Gcd10p/Gcd14p complex is the essential two-subunit tRNA(1methyladenosine) methyltransferase of Saccharomyces cerevisiae. Proc. Natl. Acad. Sci. 97: 5173.
Anderson J., Phan L., Cuesta R., Carlson B.A., Pak M., Asano K., Bjork G.R., Tamame M., and Hinnebusch A.G. 1998. The essential Gcd10p-Gcd14p nuclear complex is required for 1methyladenosine modification and maturation of initiator methionyl-tRNA. Genes Dev. 12: 3650.

Arhin G.K., Shen S., Perez I.F., Tschudi C., and Ullu E. 2005. Downregulation of the essential Trypanosoma brucei La protein affects accumulation of elongator methionyl-tRNA. Mol. Biochem. Parasitol. 144: 104.

Brescia C.C., Mikulecky P.J., Feig A.L., and Sledjeski D.D. 2003. Identification of the Hfq-binding site on DsrA RNA: Hfq binds without altering DsrA secondary structure. RNA 9: 33 .

Calvo O., Cuesta R., Anderson J., Gutierrez N., Garcia-Barrio M.T., Hinnebusch A.G., and Tamame M. 1999. GCD14p, a repressor of GCN4 translation, cooperates with Gcd10p and Lhplp in the maturation of initiator methionyl-tRNA in Saccharomyces cerevisiae. Mol. Cell. Biol. 19: 4167.

Chakshusmathi G., Kim S.D., Rubinson D.A., and Wolin S.L. 2003. A La protein requirement for efficient pre-tRNA folding. EMBO J. 22: 6562 .

Chen X., Smith J.D., Shi H., Yang D.D., Flavell R.A., and Wolin S.L. 2003. The Ro autoantigen binds misfolded U2 small nuclear RNAs and assists mammalian cell survival after UV irradiation. Curr. Biol. 13: 2206.

Cheng Z.F. and Deutscher M.P. 2003. Quality control of ribosomal RNA mediated by polynucleotide phosphorylase and RNase R. Proc. Natl. Acad. Sci. 100: 6388.

Copela L.A., Chakshusmathi G., Sherrer R.L., and Wolin S.L. 2006. The La protein functions redundantly with tRNA modification enzymes to ensure tRNA structural stability. $R N A$ 12: 644 .

Deutscher M.P. 2006. Degradation of RNA in bacteria: Comparison of mRNA and stable RNA. Nucleic Acids Res. 34: 659 .

Dong G., Chakshusmathi G., Wolin S.L., and Reinisch K.M. 2004. Structure of the La motif: A winged helix domain mediates RNA binding via a conserved aromatic patch. EMBO J. 23: 1000.

Egecioglu D.E., Henras A.K., and Chanfreau G.F. 2006. Contributions of Trf4p- and Trf5p-dependent polyadenylation to the processing and degradative functions of the yeast nuclear exosome. RNA 12: 26.

Fernandez C.F., Pannone B.K., Chen X., Fuchs G., and Wolin S.L. 2004. An Lsm2-Lsm7 complex in Saccharomyces cerevisiae associates with the small nucleolar RNA snR5. Mol. Biol. Cell 15: 2842.

Foldynova-Trantirkova S., Paris Z., Sturm N.R., Campbell D.A., and Lukes J. 2005. The Trypanosoma brucei La protein is a candidate poly(U) shield that impacts spliced leader RNA maturation and tRNA intron removal. Int. J. Parasitol. 35: 359.

Fuchs G., Stein A.J., Fu C., Reinisch K.M., and Wolin S.L. 2006. Structural and biochemical basis for misfolded RNA recognition by the Ro protein. Nat. Struct. Mol. Biol. 13: 1002.

Geissmann T.A. and Touati D. 2004. Hfq, a new chaperoning role: Binding to messenger RNA determines access for small RNA regulator. $E M B O J .23: 396$.

Goodier J.L., Fan H., and Maraia R.J. 1997. A carboxy-terminal basic region controls RNA polymerase III transcription factor activity of human La protein. Mol. Cell. Biol. 17: 5823.

He W. and Parker R. 2001. The yeast cytoplasmic LsmI/Patlp complex protects mRNA 3' termini from partial degradation. Genetics 158: 1445.

Herschlag D. 1995. RNA chaperones and the RNA folding problem. J. Biol. Chem. 270: 20871.

Houseley J. and Tollervey D. 2006. Yeast Trf5p is a nuclear poly(A) polymerase. EMBO Rep. 7: 205.

Huang H.R., Rowe C.E., Mohr S., Jiang Y., Lambowitz A.M., and Perlman P.S. 2005. The splicing of yeast mitochondrial group I and group II introns requires a DEAD-box protein with RNA chaperone function. Proc. Natl. Acad. Sci. 102: 163.

Huang Y., Bayfield M.A., Intine R.V., and Maraia R.J. 2006. Separate RNA-binding surfaces on the multifunctional La protein mediate distinguishable activities in tRNA maturation. Nat. Struct. Mol. Biol. 13: 611. 
Inada M. and Guthrie C. 2004. Identification of Lhp1p-associated RNAs by microarray analysis in Saccharomyces cerevisiae reveals association with coding and noncoding RNAs. Proc. Natl. Acad. Sci. 101: 434.

Johansson M.J. and Bystrom A.S. 2002. Dual function of the tRNA(m(5)U54)methyltransferase in tRNA maturation. RNA 8: 324 .

Kadaba S., Wang X., and Anderson J.T. 2006. Nuclear RNA surveillance in Saccharomyces cerevisiae: Trf4p-dependent polyadenylation of nascent hypomethylated tRNA and an aberrant form of 5S rRNA. RNA 12: 508 .

Kadaba S., Krueger A., Trice T., Krecic A.M., Hinnebusch A.G., and Anderson J. 2004. Nuclear surveillance and degradation of hypomodified initiator tRNA ${ }^{\text {Met }}$ in $S$. cerevisiae. Genes Dev. 18: 1227.

LaCava J., Houseley J., Saveanu C., Petfalski E., Thompson E., Jacquier A., and Tollervey D. 2005. RNA degradation by the exosome is promoted by a nuclear polyadenylation complex. Cell 121: 713.

Lease R.A. and Woodson S.A. 2004. Cycling of the Sm-like protein Hfq on the DsrA small regulatory RNA. J. Mol. Biol. 344: 1211.

Li Z., Pandit S., and Deutscher M.P. 1998. Polyadenylation of stable RNA precursors in vivo. Proc. Natl. Acad. Sci. 95: 12158.

Li Z., Reimers S., Pandit S., and Deutscher M.P. 2002. RNA quality control: Degradation of defective transfer RNA. EMBO J. 21: 1132.

Mayes A.E., Verdone L., Legrain P., and Beggs J.D. 1999. Characterization of Sm-like proteins in yeast and their association with U6 snRNA. EMBO J. 18: 4321.

Mikulecky P.J., Kaw M.K., Brescia C.C., Takach J.C., Sledjeski D.D., and Feig A.L. 2004. Escherichia coli Hfq has distinct interaction surfaces for DsrA, rpoS and poly(A) RNAs. Nat. Struct. Mol. Biol. 11: 1206

Mohanty B.K. and Kushner S.R. 1999. Analysis of the function of Escherichia coli poly(A) polymerase I in RNA metabolism. Mol. Microbiol. 34: 1094.

Mohanty B.K., Maples V.F., and Kushner S.R. 2004. The Smlike protein Hfq regulates polyadenylation dependent mRNA decay in Escherichia coli. Mol. Microbiol. 54: 905.

Mohr S., Stryker J.M., and Lambowitz A.M. 2002. A DEADbox protein functions as an ATP-dependent RNA chaperone in group I intron splicing. Cell 109: 769.

Moll I., Leitsch D., Steinhauser T., and Blasi U. 2003a. RNA chaperone activity of the Sm-like Hfq protein. EMBO Rep. 4: 284.

Moll I., Afonyushkin T., Vytvytska O., Kaberdin V.R., and Blasi U. 2003b. Coincident Hfq binding and RNase E cleavage sites on mRNA and small regulatory RNAs. RNA 9: 1308 .

Moller T., Franch T., Hojrup P., Keene D.R., Bachinger H.P., Brennan R.G., and Valentin-Hansen P. 2002. Hfq: A bacterial Sm-like protein that mediates RNA-RNA interaction. Mol. Cell 9: 23.

Moore P.B. and Steitz T.A. 2003. The structural basis of large ribosomal subunit function. Annu. Rev. Biochem. 72: 813.

O'Brien C.A. and Wolin S.L. 1994. A possible role for the $60 \mathrm{kd}$ Ro autoantigen in a discard pathway for defective $5 \mathrm{~S}$ ribosomal RNA precursors. Genes Dev. 8: 2891.

Pannone B.K., Xue D., and Wolin S.L. 1998. A role for the yeast La protein in U6 snRNP assembly: Evidence that the La protein is a molecular chaperone for RNA polymerase III transcripts. EMBO J. 17: 7442

Pannone B.K., Kim S.D., Noe D.A., and Wolin S.L. 2001. Multiple functional interactions between components of the Lsm2-Lsm8 complex, U6 snRNA, and the yeast La protein. Genetics 158: 187.

Park J.M., Kohn M.J., Bruinsma M.W., Vech C., Intine R.V., Fuhrmann S., Grinberg A., Mukherjee I., Love P.E., Ko M.S., et al. 2006. The multifunctional RNA-binding protein La is required for mouse development and for the establishment of embryonic stem cells. Mol. Cell Biol. 26: 1445.

Salgado-Garrido J., Bragado-Nilsson E., Kandels-Lewis S., and Seraphin B. 1999. Sm and Sm-like proteins assemble in two related complexes of deep evolutionary origin. EMBO J. 18: 3451 .

Schroeder R., Barta A., and Semrad K. 2004. Strategies for RNA folding and assembly. Nat. Rev. Mol. Cell Biol. 5: 908.

Schumacher M.A., Pearson R.F., Moller T., Valentin-Hansen P., and Brennan R.G. 2002. Structures of the pleiotropic translational regulator $\mathrm{Hfq}$ and an Hfq-RNA complex: A bacterial Sm-like protein. EMBO J. 21: 3546.

Schumperli D. and Pillai R.S. 2004. The special Sm core structure of the U7 snRNP: Far-reaching significance of a small nuclear ribonucleoprotein. Cell. Mol. Life Sci. 61: 2560.

Shi H., O’Brien C.A., Van Horn D.J., and Wolin S.L. 1996. A misfolded form of $5 \mathrm{~S}$ rRNA is associated with the Ro and La autoantigens. RNA 2: 769 .

Shimaoka M., Takagi J., and Springer T.A. 2002. Conformational regulation of integrin structure and function. Annu. Rev. Biophys. Biomol. Struct. 31: 485.

Stein A.J., Fuchs G., Fu C., Wolin S.L., and Reinisch K.M. 2005. Structural insights into RNA quality control: The Ro autoantigen binds misfolded RNAs via its central cavity. Cell 121: 529.

Storz G., Altuvia S., and Wassarman K.M. 2005. An abundance of RNA regulators. Annu. Rev. Biochem. 74: 199.

Storz G., Opdyke J.A., and Zhang A. 2004. Controlling mRNA stability and translation with small, noncoding RNAs. Curr. Opin. Microbiol. 7: 140.

Teplova M., Yuan Y.R., Phan A.T., Malinina L., Ilin S., Teplov A., and Patel D.J. 2006. Structural basis for recognition and sequestration of UUU $(\mathrm{OH}) 3^{\prime}$ temini of nascent RNA polymerase III transcripts by La, a rheumatic disease autoantigen. Mol. Cell 21: 75 .

Tharun S., He W., Mayes A.E., Lennertz P., Beggs J.D., and Parker R. 2000. Yeast Sm-like proteins function in mRNA decapping and decay. Nature 404: 515.

Vanacova S., Wolf J., Martin G., Blank D., Dettwiler S., Friedlein A., Langen H., Keith G., and Keller W. 2005. A new yeast poly(A) polymerase complex involved in RNA quality control. PLoS Biol. 3: e189.

Verdone L., Galardi S., Page D., and Beggs J.D. 2004. Lsm proteins promote regeneration of pre-mRNA splicing activity. Curr. Biol. 14: 1487.

Wolin S.L. and Cedervall T. 2002. The La protein. Annu. Rev. Biochem. 71: 375 .

Wyers F., Rougemaille M., Badis G., Rousselle J.-C., Dufour M.-E., Boulay J., Regnault B., Devaux F., Namane A., Seraphin B., et al. 2005. Cryptic pol II transcripts are degraded by a nuclear quality control pathway involving a new poly(A) polymerase. Cell 121: 725 .

Xue D., Rubinson D.A., Pannone B.K., Yoo C.J., and Wolin S.L. 2000. U snRNP assembly in yeast involves the La protein. EMBO J. 19: 1650.

Yoo C.J. and Wolin S.L. 1997. The yeast La protein is required for the 3 ' endonucleolytic cleavage that matures tRNA precursors. Cell 89: 393.

Zaric B., Chami M., Remigy H., Engel A., Ballmer-Hofer K., Winkler F.K., and Kambach C. 2005. Reconstitution of two recombinant $\mathrm{LSm}$ protein complexes reveals aspects of their architecture, assembly and function. J. Biol. Chem. 22: 16066.

Zhang A., Wassarman K.M., Ortega J., Steven A.C., and Storz G. 2002. The Sm-like Hfq protein increases OxyS RNA interaction with target mRNAs. Mol. Cell 9: 11.

Zhang A., Wassarman K.M., Rosenow C., Tjaden B.C., Storz G., and Gottesman S. 2003. Global analysis of small RNA and mRNA targets of Hfq. Mol. Microbiol. 50: 1111. 


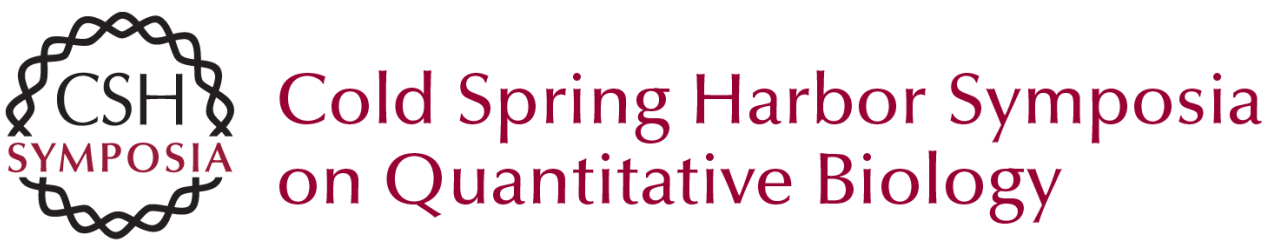

\section{Molecular Chaperones and Quality Control in Noncoding RNA Biogenesis}

S.L. WOLIN and E.J. WURTMANN

Cold Spring Harb Symp Quant Biol 2006 71: 505-511

Access the most recent version at doi:10.1101/sqb.2006.71.051

References This article cites 67 articles, 31 of which can be accessed free at: http://symposium.cshlp.org/content/71/505.full.html\#ref-list-1

License

Email Alerting Receive free email alerts when new articles cite this article - sign up in Service the box at the top right corner of the article or click here. 